\title{
Cognitive, Emotional and Behavioral Reactions to Corporate Rebranding: Do NFC and Ambivalence Matter?
}

\author{
Phang Ing \\ Universiti Malaysia Sabah
}

\begin{abstract}
The present paper aims to serve two purposes. The first one is to investigatethe influence of intrinsic motivation suchas the need for cognition on ambivalence towards rebranding and secondly, how individuals with different ambivalence levels react in terms of cognition, emotion and behavioral intention to corporate rebranding. The findings provide better understanding to the expensive and risky corporate rebranding program, by supporting the existence of ambivalent attitudes. Firstly, individuals with a high need for cognition tend to experience higher ambivalent attitudes hence have a higher tendency to put buying decisions on hold. Secondly, high-ambivalence individuals try to search for more information which eventually lead them to put buying decisions on hold, due to their high psychological discomfort. Procrastination and amplification effects are clearly evident among them. Conversely, low-ambivalence individuals prefer to choose approach responses over procrastination. Differences in cognition and behavioral intentions are evident imply the need for appropriate planning and implementation of corporate rebranding strategy.
\end{abstract}

Keywords: ambivalence, corporate rebranding, need for cognition, buying intention

\section{Introduction}

The attitude polarization paradigm (Tesser and Leone, 1977) posits that the longer an individual considers an attitude object, the more polarized his attitude would be. In view of corporate brands, peoples' attitudes toward the brands should be more consistent when they possess greater knowledge about the said brands and have a higher need to process information. Similarly, consumers would prefer the corporate rebranding of a familiar rather than an unfamiliar brand. However, reality tells us that many established firms failed in their corporate rebranding effort and corporate rebranding is risky, challenging and costly (Dunham, 2002) with an approximately 20 percent success rate (Trond, Fiskund, Tornblom, and Hogna, 1997). Review of organizational change and corporate rebranding studies also indicates that consumer reactions to change range from conformity, indifference, ambivalence to resistance (Oreg and Sverdlik, 2011). In an imposed change such as corporate rebranding, 
consumers are found to experience more ambivalence (Oreg and Sverdlik, 2011) as their attitudes are heightened by uncertain and ambiguous future outcomes, and the "opportunity for novelty is combined with a restriction rather than promotion, of one's personal expression" (Sverdlik and Oreg, 2009, p.1438).

These researchers challenge that knowledge-consistency link is not always true (Judd and Krosnick, 1989; Tetlock, 1989). Polarization might not happen (Liberman and Chaiken, 1991) as prolonged thoughts could result in less coherent schema based upon inconsistent or disjointed beliefs (Wilson, Kraft, and Dunn, 1989).As intrinsic motivation reflects how much "individuals engage in and enjoy effortful thinking" (Cacioppo and Petty, 1982, p. 116), a higher need to cognitively process information triggers the processing of both positive and negative attitudes and leads to higher ambivalence. However, other ambivalence researchers found a negative relationship between the need for cognition (NFC) and ambivalence, attributed to the inherently positive nature of high NFC individuals to enjoy elaborate information-processing and a higher tolerance toward conflicting messages (e.g. Thompson and Zanna, 1995; Thompson, Zanna, and Griffith, 1995). These contradicted findings in NFC-related ambivalence studies cause confusion and lead one to question the NFCinfluences in an imposed change condition such as a corporate rebranding.

Confusing conclusions are also found inambivalence-behavioral intention link. Review of literature indicates that high-ambivalence individuals who experience higher psychological discomfort (Bell and Esses, 2002; Newby-Clark, McGregor and Zanna,2002; Nordgren, van Harreveld and van der Plight, 2006)will trysearching for more information (Maio, Bell, and Esses, 1996; Jonas, Diehl, and Bromer, 1997). They rely less on heuristic cues (Basinger and Lavine, 2005; Lavine, Christopher and Steenbergen, 2012) which later result in moderation in decision making (Lavine, 2001; van Harreveld, Rutjens, Nordgren, and van der Plight, 2009). However, other ambivalence researchers posit that ambivalence is only unpleasant when people are forced to make a choice (Pang and Keh, 2012; van Harreveld et al., 2009) and there is a possibility that heuristic rather than systematic information-processing is adopted by high-ambivalence individuals (Gunasti and Ross, 2010; Zemborani and Johar, 2007).

Marketers could stand a better chance incorporate rebranding success by understanding what causes ambivalence and how ambivalence leads to differences in consumers' cognitive, emotional and behavioral intention responses. While ambivalence has been evidenced in qualitative corporate rebranding studies under many settings (e.g. Daly and Maloney, 2011; Oberg, Gurnstorm and Johnson, 2011; Stuart and Muzellec, 2004; Yang, Davis and Robertson, 2012), it has yet to be empirically examined. It is unclear how high-ambivalence individuals could have reacted differently in a corporate rebranding. This paper aims to first study the role of intrinsic motivation (e.g. NFC) in corporate rebranding-related ambivalent attitudes, whether high NFC leads to higher ambivalence towards rebranding; secondly, the study further provides comparisons across individuals with highvs. low-levels of ambivalent attitudes in terms of ambivalence-behavioral link and also their cognitive and emotional responses. The findings are important in providing useful insight to marketers and academicians in planning for their multi-million dollar corporate rebranding program. 


\section{Need for cognition (NFC)}

Thompson and Zanna (1995) posit that NFC is a valid antecedent to ambivalence and high-NFC results in the utilization of more cognitive effort in the processing of an attitude object and a greater tolerance of conflicted arguments. However, other researchers such as Hanze (2001), Judd and Krosnick (1989) and Tetlock (1989) claim that the knowledge-consistency link is not always true and prolonged thought in an ambivalent and conflicted situation could result in moderation in attitude (Tesser and Leone, 1977) and lead to less coherent schema (Wilson et al., 1989) which creates opportunity for ambivalence to develop.

Borrowingfrom the Elaboration Likelihood Model, high-NFC individuals are expected to take the central route of information-processing. For example, in a product evaluation situation, high-NFC individuals tend to "engage in in-depth processing and careful evaluation of the message claims" (Ting, 2012, p. 532). They "enjoythe process of analyzing and processing discrete product related information", and tend to "judge a product quality based on reasons related to product attributes" (p. 532).Accordingly, they tend to use their prior knowledge in the assessment process as they are better at remembering previously presented information (e.g. Cacioppo, Petty, and Morris, 1983; Lassiter, Briggs, and Bowman, 1991). Again, this has nothing to do with their intellectual capacity, but their higher tolerance of cognitive load compared to low-NFC individuals (Ting, 2012).

Effortful thought is a process that increases individuals' exposure to potentially conflicting consideration which creates an opportunity for ambivalence to develop (Rudolph and Popp, 2007). As high-NFC individuals think more and depend more on the task specific self-concept (Dickhauser and Reidhard, 2006), they use prior knowledge in the assessment process and end up with better recall (e.g. Cacioppo, Petty, and Morris, 1983; Lassiter et al., 1991). In other words, they could recallboth positive and negative information and be influenced by it. Importantly, their enjoyment over the elaborated cognitive processing does not imply that they will process only one-sided information. It also does notensurethat only a univalent outcome will be produced (only positive or only negative valence).

This is especially true for M\&A induced corporate rebranding involving highly familiar corporate brands. The knowledge structure of both parent brands are well established and the availability of the extensive network associations formed around brand names allow the new information to come into contact with more points of the existing information, whichprotect or prevent the attitude from interference, disassociation or decay. In fact, conflicted organizational information has been evident in many organizational change studies (Brooks and Highhouse, 2006; Gardberg and Fomburn, 2002). High-NFCindividualswho do not mind processing in an in-depth mannerevaluate message claims carefully (Ting, 2012; Wood, Kallgren, and Priesler, 1985). Prolonged thinking insuch a situation allows the retrieval of more information which could be conflicted in nature (Thompson and Zanna, 1995), leadingto higher ambivalent attitudes (Keele and Wolak, 2008). As such, highNFC individuals might prefer to put their decision on hold and search for more information to assist decision making (Hanze, 2001). 
Compared to their high NFC counterparts who process information in a detailed manner, low-NFC individuals are not motivated to pay attention to the underlying conflicted reactions. As a result, they experience less ambivalence andareless interested in analyzing and processing specific information. They also have the tendency to depend on a single, simple association or inference(Haugtvedt and Petty, 1992) and emphasize on the dominant reactions while ignoring the contradicted reactions. In a consumer setting where attitudes are normally formed via evaluative conditioning (e.g. less propositional brand attitudes in the construction of explicit attitudes; Zimmerman, Redker, and Gibson, 2011), low-NFC individuals will depend on peripheral cues, causing themselves to be more likely to change as a result of simple cues in the persuasion context (Haugtvedt, Petty and Cacioppo, 1986). These individuals "fail to follow the logic and meaning behind the complex message, miss vital arguments and deliberate only briefly about product information" (Nkwocha et al. 2005 in Ting, 2012, p. 532).There is a higher tendency to choose "buy rebrand brand' and 'buy other brands' over the 'hold buying' option. Hence,

H1a: High-NFC individuals experience higher ATR than low-NFC individuals.

H1b: High-NFC individuals have higher intention to hold their buying compared to their low-NFC counterparts, while low ambivalence individuals prefer to 'buy rebranded brand' and 'buy other brands'.

\section{Ambivalence towards Rebranding andConsequences}

Ambivalence literature indicates that ambivalent feelings are frequently associated with unpleasantness (van Harreveld, van der Plight and van Liver, 2009) and psychological discomfort (Bell and Esses, 2002; Newby-Clark, et al., 2002; Nordgren et al.,2006). Thisambivalence could be alleviated by either: a) cognitive processing of relevant information or b) making a choice (van Harreveld et al., 2009).However, it is not easy for ambivalent individuals to choose which side of their attitudes to depend on due to the simultaneously experienced moderate to strong conflicted attitudes.

It is a psychological state in which "a person holds mixed feelings toward some psychological objective" (Gardner, 1987, p. 241) and "a subset of conflict (which is) distinguished from conflict primarily by the presence of both positive and negative poles, with equivalently strong evaluations" (Thompson et al., 1995, p. 367). Highambivalence individuals are hence motivated to search for and process more information to alleviate the psychological discomfort caused by this indecision (Maio et al., 1996; Jonas et al., 1997). In the studies examining ambivalent attitudes toward Black and White men, Hass, Katz, Rizzo, Bailey and Eisenstaedt (1991) found amplification effects in ambivalent situations. Similarly, Bell and Esses's (1997; 2002) studies in assessing ambivalent attitudes toward Native people in Canada also linked ambivalence to amplification responses. Respondents portrayed larger differences in positive and negative mood states when evaluating Native or Black people compared to White people. It is these amplification effects that differentiate an indifferent individual from a highly ambivalent individual. Amplification allows for development of attitude which serves as a stronger drive for behaviors, whereasindifferent individuals hold weak attitudes toward the issue.It is hence postulated that high-ambivalence prompts for amplification than people with univalence attitudes in terms of their attitude and behavioral responses to a corporate rebranding. 
As for making a choice, ambivalence literature presents contradicting findings on the ambivalent attitude-behavior link. Though many research posit ambivalence as a weak behavioral predictor, studies that work on attitude objects, other than the environment, show that ambivalence has a direct effect on behavioral intention (e.g. Conner and Flesh, 1998; Hanze, 2001; Thompson and Holmes, 1996). In Hanze's (2001) study of German attitudes toward NATO's military invasion in the Kosovo war, ambivalence was significantly related to action tendencies such as reactions, avoidant and amplification responses, in which highly ambivalent individuals clearly preferredthe amplification option. Based on consumer buying decision, highambivalence individuals search for more information (amplification), even though buying is not yet made. Conversely, low-ambivalence individuals hold more univalent attitudes that are more readily accessible and "more likely to bias the perceptions of the attitude object and the context in which the behavior is performed" (Conner and Armitage 2008, p. 275).

In the majority of the marketing studies,consumer attitudes are measured using semantic differential scales to reflect their overall evaluation toward the brand or product (e.g. $1=$ very unfavorable and $7=$ very favorable); and behavioral intention scales are measured with"buy" or "not buy" options or a single bipolar item (e.g. 1= definitely not buy and 7= definitely will buy). As approach and withdrawals are presumed to be reciprocally activated behavior manifestations, individuals are expected to choose either approach or withdrawal in a decision making.

Some marketers generalize and group 'withdrawal' and 'holding'responses into one category as the assessment outcomes are equivalent to "not buying". This could be problematic because although the overt behaviors are similar, the underlying cognitive and affective states could be different and varied. An individual who does not favor norbuy a brand is different from another person who puthis buying decision on holdbecause he is ambivalent. In the former case, there is little chance for marketers to alter the decisions of those who dislikea brand. Convincing a person who already has favorable attitudes toward a brand is easier, eventhough he simultaneously holdsunfavorable attitudes. Instead, thesepositive and negative attitudes from moderate to high intensitycause the individual to search for more information about the brand. There isa high possibility for the formation of enduring attitudesthatturns him intoa loyal customer. It is rather presumptuous to define consumer purchase intention as being "willing to buy" and "not willing to buy".

Furthermore, it is common for consumers to put their buying decisions on hold (Dhar and Kim, 2007), especiallywhen they could not decide on which choice to make. The somewhat attractive choice alternative fails to dominate over the other alternatives and indecision draws them to delay decision making.From a normative standpoint, high-ambivalenceindividuals will then deal with the decision problem intensely (Hanze, 2001), adoptinga wider selection of attributes as important for evaluation (van Harreveld et al., 2004). More effort and deliberation (Jonas, et al., 1997; Maio, et al., 1996) are invested to provide description in a more systematic (Maio et al. 1996) and controlled manner (Cunningham, Johnson, Gatenby et al., 2003).

As such, in a corporate rebranding, high-ambivalence might put a stop to the decision making (Hanze, 2001). Individuals will tend to choose to hold their buying decision 
over approach and withdrawal options. Conversely, low-ambivalence individuals will have less conflicted reactions causing them to feel no psychological discomfort. Their more polarized attitudes will assist choice selection, by committing to either 'willing to buy rebranded brand' or 'willing to buy other brands' options, rather than the 'hold buying' decision. Hence,

H2a: High ambivalenceleads to psychological discomfort.

H2b: High ambivalence leads to higher information search intention.

H3a: Individuals with high ambivalence prefer the "hold buying" option over "buy rebranded brand" and "buy other brands" options.

H3b: Individuals with low ambivalence prefer the "buy rebranded brand" and "buy other brands" options over the "hold buying" option.

\section{Methodology}

Prior to the main test, several pretests were carried out to determine the selection of corporate brand category and also the suitability of the news announcement. In the first pretest, 25students from a Malaysian public university were tested for their attitudes toward fourcomputer brand names, using brand familiarity scalesuggested by Simonin and Ruth (1998). Two most familiar corporate brand names (i.e. Apple and Dell) were adopted for the main study.

The proposition of corporate rebranding as an imposed change situation that induces ambivalence can only be further supported when consumers react ambivalently even in a positively viewed news announcement condition. An ideal announcement should be viewed neutral to positively based on simple logic that news announcements released by firms are designed to convey only positive message.In the third pretest, a total of 15 students were asked to rate the rebranding announcement (i.e. aspositive, neutral or negative). The results of the pretest indicated that all respondents rated the new announcement to be 'positive' and 'neutral'. There was no negative response recorded.

A total of 213 valid questionnaires were utilized in the main study (156 female, $\mathrm{M}_{\text {age }}=$ 20). Respondents were first asked to rate their attitudes toward Dell and Apple Inc. Theythen read a simple announcement informing the merger and rebranding betweenApple Inc. and Dell Computer. They were asked to rate their ambivalence towards rebranding (Thompson and Zanna, 1995; Thompson et al., 1995); and the level of discomfort felt toward the rebranding using a one item-7-point scale (i.e. $1=$ uncomfortable and $7=$ comfortable). Next, they were asked to rate their buying intention and wrote down what made them select their choices in a 3-minute-thought listing task. These thoughts were coded by two independent judges into: choice reasons (not sure or wish to look for more information, indifference between the rebranded brand and other brands, prefer other brands and lastly, prefer the parent brands) and the number of thoughts. The agreement rateswere93.1\% and 93.55\%, with the estimated reliabilities of. 824 and .835(Perreault and Leigh, 1989). Finally, they were asked to fill in their personal information and rate the Need for Cognition (NFC) scale (Cacioppo, Petty, and Kao, 1984) which consisted of 18 items on a 7point scale, upon debriefing. However, item 5 and 7 of the 18-item scale are found to have low coefficient values and both were deleted from the scale. The 16-item scale 
produced Cronbach alpha of .978 with correlated tem-total correlation scores ranged from .838 to .867 . The factor analysis also produced one component with factor loadings ranged from .858 to .880 .

\section{Findings of the Main Study}

Hypothesis 1a presumes that high-Need for Cognition (NFC) individuals will experience higher ambivalence towards rebranding (ATR) than low-NFC individuals. A one way ANOVA was carried out to test this hypothesis, withhigh-NFC individuals coded as 1 and low-NFC individuals as 0 , using median split. The results in Table 1 showed that high NFC group $(M=9.196, \mathrm{SD}=2.197)$ was indeed experiencing significantly higher ATR than the low NFC group $(M=1.594, \mathrm{SD}=2.579), F(1,212)=$ $539.243, p<.0001$. Due to the significant Levene's test of equality of error variance, the data were re-tested using the Kruskal-Wallis test. The test produced $\chi^{2}(1,213)=$ $139.574, p<.0005$. Both the ANOVA and Kruskal-Wallis test results supported hypothesis 1a.

Table 1: Mean and SD for ambivalence towards rebranding by need for cognition

\begin{tabular}{|c|c|c|c|}
\hline Need for Cognition & $\mathrm{N}$ & Mean & SD \\
\hline Low & 101 & 1.594 & 2.579 \\
\hline High & 112 & 9.196 & 2.197 \\
\hline Total & 213 & 5.592 & 4.488 \\
\hline
\end{tabular}

Hypothesis $1 \mathrm{~b}$ postulates that high-NFC individuals have a comparatively higher tendency to hold their buying decision due to their high ambivalence level; while lowNFC individuals tend to adopt approach and withdrawal options ("buy rebranded brand" or "buy other brands"). The results in table 2 showed that there were significant differences between the two NFC groups in terms of their choice task, $\chi^{2}$ $(1,213)=137.2, p<.0001$. The high NFC group indeed tended to choose "hold" option $(\mathrm{n}=100,91 \%)$ over the "buy rebranded brand" and "buy other brand" $(\mathrm{n}=10,9 \%)$, and choice options were significantly different at $p<.05$ level. The result hence supported hypothesis $1 b$.

Table 2: Cross tabulations by choice task option and need for cognition

\begin{tabular}{|c|c|c|c|c|}
\hline & & Choice of buying intel & & \\
\hline & & $\begin{array}{c}\text { Buy the rebranded brand and } \\
\text { buy other brand }\end{array}$ & $\begin{array}{c}\text { Hold } \\
\text { buying }\end{array}$ & Total \\
\hline Need For Cognition & Low & $92_{\mathrm{a}}$ & $11_{\mathrm{b}}$ & 103 \\
\hline & High & $10_{\mathrm{a}}$ & $100_{\mathrm{b}}$ & 110 \\
\hline
\end{tabular}

Hypothesis 2 examines howambivalent individuals generally feel and react to their ambivalent state of emotion in a corporate rebranding announcement. Highambivalence individuals are expected to experience a larger amount of psychological discomfort $(\mathrm{H} 2 \mathrm{a})$ and have more intention to search for more information $(\mathrm{H} 2 \mathrm{~b})$.

A simple regression analysis was conducted to test this relationship and the results supported hypothesis $2 \mathrm{a}$ in that high-ambivalence led to more psychological discomfort (refer to table 3$)$. The 7 -point Feeling scale ( $1=$ not comfortable at all, $7=$ 
very comfortable) confirmed a significant negative impact of ambivalence towards rebranding (ATR) on feeling ( $\beta=-.836, p<.0001)$. The $\mathrm{R}^{2}$ of the model was .699 which meant that ambivalence towards rebranding explained about $70 \%$ of the variance in feelings toward corporate rebranding.

Table 3: Simple regression result for atr on feelings toward corporate rebranding

\begin{tabular}{|c|c|c|c|c|c|c|c|c|c|}
\hline \multicolumn{4}{|c|}{ Coefficients } & \multicolumn{6}{|c|}{ Diagnostic Statistics } \\
\hline Model & $\begin{array}{l}\text { Standardized } \\
\text { Coefficients }\end{array}$ & $\mathrm{T}$ & Sig. & $\mathrm{R}^{2}$ & $\begin{array}{c}\text { Adjusted } \\
\mathrm{R}^{2}\end{array}$ & $\mathrm{~F}$ & dfl & $\mathrm{df} 2$ & $\begin{array}{l}\text { Sig. } \\
\text { F }\end{array}$ \\
\hline & Beta & & & & & & & & \\
\hline (Constant) & - & 59.734 & .000 & 699 & .698 & 490.316 & 1 & 211 & .000 \\
\hline $\begin{array}{l}\text { Ambivalence } \\
\text { towards } \\
\text { rebranding } \\
\text { (ATR) }\end{array}$ & -.836 & 22.143 & .000 & & & & & & \\
\hline
\end{tabular}

Hypothesis $2 \mathrm{~b}$ postulates that high-ambivalence individuals will have a higher intention to search for more information. The intention to search for more information could be reflected by their stated intention in the thought listing task or implied by the number of thoughts that come to their mind (reflects how much they are willing to think more about the issue at hand).

A crosstab was tabulated to compare the thought listings among individuals'different levels of ambivalence toward rebranding. Four categories of thought listing tasks were identified: (1) indecisiveness or search for more information; (2) indifferences (i.e. prefer neither brand nor feeling anything); (3) preference over other brands; and lastly (4) the parent brand preferences (i.e. prefer or dislike the parent brands). Indecisiveness and amplification were combined as these were the common effects of ambivalent attitudes. The first category was coded as 1 , while the rest of the three groups were coded as 0 for crosstab tabulation, as some of the cells had expected counts of less than five. 89 out of the total of 108 like to search for more information, $\chi^{2}(1,213)=126.74, p<.0001$. Only minority of themreflected the tendency of being indifferent or had made their choice due to preferences over other brands. There was a significant difference between "indecisiveness and search for more information" with the other three options at $\mathrm{p}<.05$ level.The majority of low-ambivalence individuals were found to make their choice based on their preferences or loyalty (or lack of preferences or loyalty) over the corporate brands (99 out of 105, or 94\%).

Next, the numbers of thought listings were cross-checked to provide more support for hypothesis testing. A crosstab was tabulated to compare consumer ambivalence and their number of thought listings (refer to table 4). Similar to the procedure before, respondents with 'only one thought' were coded as 1 and 0 for 'more than one thought'. The majority of the respondents were found to list down only one thought (about 74\%). Nevertheless, the results indicated that people with higher ambivalence level had 'more than one thought' (up to four thoughts, $\mathrm{n}=38,35 \%$ ) compared to those with low $(\mathrm{n}=17,16 \%)$ ambivalence, $\chi^{2}(6,213)=10.03, p<.01$. The results supported the proposed hypothesis thathigh-ambivalence individuals tended to think more about the issue investigated and hence were more motivated to search for more information. 
Both thought listing and numbers of thought results provided complementarysupport forhypothesis $2 b$.

Table 4: Crosstabulation by number of thoughts and ambivalence levels

\begin{tabular}{|l|l|c|c|c|}
\hline \multirow{2}{*}{\multicolumn{2}{|c|}{}} & \multicolumn{2}{|c|}{ Number ofThoughts } & Total \\
\cline { 3 - 5 } & One thought & More than 1 thought & \\
\hline $\begin{array}{l}\text { Ambivalence toward } \\
\text { rebranding }\end{array}$ & Low & $88_{\mathrm{a}}$ & $17_{\mathrm{b}}$ & 105 \\
\cline { 2 - 5 } & High & $70_{\mathrm{a}}$ & $38_{\mathrm{b}}$ & 108 \\
\hline $\begin{array}{l}\text { Each subscript letter denotes a subset of NoofThoughts categories whose column proportions do not differ } \\
\text { significantly from each other at the .05 level. }\end{array}$
\end{tabular}

Hypothesis 3a postulates that high-ambivalence individuals tend to prefer the hold buying' option over the other two options, whilst their low-ambivalence counterparts tend to choose 'buy rebranded brand' and 'buy other brands' over the 'hold' option (hypothesis $3 \mathrm{~b}$ ). A crosstab was tabulated to compare the two ambivalent groups and their choices of buying intention. The results in table 5showed that the majority of the high-ambivalence individuals indeed tended to hold their buying decision (93.5\%) over 'buy other brands' and 'buy branded brand' (6.5\%) and this supported hypothesis3a. This option was significantly different from the other two options at $p<$. 05 levels.

Conversely, low-ambivalence individuals tended to choose 'buy rebranded brand' $(62 \%)$ and 'buy other brands' (28.6\%) over 'hold buying' options (1\%), supporting hypothesis $3 \mathrm{~b}$. The option of 'buy rebranded brand' was significantly different from 'buy other brands' and 'hold buying' options for both low and high-ambivalence individuals. Even though the chi square testwas unable to be performed, the results provided clear indications in support of hypotheses $3 \mathrm{a}$ and $3 \mathrm{~b}$.

Table 5: Crosstabulation by choice task options and ambivalence levels

\begin{tabular}{|l|l|r|r|r|r|}
\hline \multirow{2}{*}{} & \multicolumn{3}{|c|}{ Choice of buying intention } & \multirow{2}{*}{ Total } \\
\cline { 2 - 5 } & $\begin{array}{c}\text { Buy the rebranded } \\
\text { brand }\end{array}$ & Buy other brand & $\begin{array}{c}\text { Hold the buying } \\
\text { decision }\end{array}$ & \\
\hline \multirow{2}{*}{ Ambivalence } & Low & $65_{\mathrm{a}}$ & $30_{\mathrm{b}}$ & $10_{\mathrm{c}}$ & 105 \\
\cline { 2 - 6 } & High & $0_{\mathrm{a}}$ & $7_{\mathrm{b}}$ & $101_{\mathrm{c}}$ & 108 \\
\hline
\end{tabular}

Binary logistic regression was conducted to provide further examination and comparison of each of the ambivalent groups in term of their choice options. The choice task option was grouped into 'buy rebranded brand and buy other brands' and 'hold buying'. The finalmodel produced $\chi^{2}(1,213)=177.014, p<.0001$. Highambivalence individuals significantly preferred 'hold buying' over 'buy rebranded brand and buy other brands', Wald=91.959, Exp (B)=137.071, $p<.0001$ than lowambivalence individuals; and low-ambivalence individuals preferred 'buy rebranded brand and buy other brands' than 'hold buying' option. These results supported hypotheses $3 \mathrm{a}$ and $3 \mathrm{~b}$.

\section{Discussion of Findings}


The current study serves to answer three research objectives: a) whether intrinsic motivation (e.g. NFC) significantly influences ambivalence towards rebranding; b) whether ambivalence towards rebranding in turn influences behavioral intention; and c) whether individuals with different levels of ambivalence towards rebranding differ in terms of their cognitive and emotional reactions and behavioral intention.

The findings of the study indicate that high-NFC induces higher ambivalence. This finding supported Hanze (2001), Judd and Krosnick (1989) and Tetlock (1989)'s propositions, but contradicted Thompson and Zanna's (1995). One possible explanation could be that high-NFC individuals who enjoy effortful thinking (Cacioppo and Petty, 1982) think and consider more,especially in an imposedambivalencesituation, allowing the retrieval of more information that could be conflicted in nature. They hold more information on highly familiar rebranded companies. The corporate rebranding causes more uncertainty and ambiguity to the future outcomes, even though they do hope that the rebranding will end well. The cognitive valence could be mixed, rather than univalent, regardless of their enjoyment over elaborated cognitive processing. The results of the number of thoughts generated by these individuals further support this hypothesis. Even though the majority of them produced only one thought $\left(\mathrm{NFC}_{\text {high }}=73\right.$ and $\left.\mathrm{NFClow}_{\text {low }}=85, \mathrm{p}<.05\right)$, there was higher numbers of high-NFC individuals produced more than one thought $\left(\mathrm{NFC}_{\text {high }}=37\right.$ and $\mathrm{NFC}_{\text {low }}=18$ ). In brief, high-NFC individuals engage in the more elaborated processingof information and enjoy the process of analyzing the information available, which in this case could be positive and negative information.

Conversely, low-NFC individuals are not motivated to pay much attention to their underlying conflicted reactions and lead to the adoption of more heuristic processing (Haugtvedt and Petty,1992; Wood et al., 1985). For these individuals, the information is processed briefly (Nkwocha et al. 2005 in Ting, 2012) and the risk involved will be grossly underestimated as these risks are difficult to conceive or simply do not come to mind. They were less interested in analyzing and processing specific information and have a tendency to depend on preference over the parent brands. The findings also show that high-NFC individuals have higher tendency to hold their buying decision (procrastination). For low-NFC individuals, a successful product line, for instance,could be used as an exemplar to determine the ability to excel in another business venture; successful examples from both parent brands could be drawn to increase the chances of successful corporate rebranding outcomes. Such individuals should choose the approach or withdrawal options more than procrastination.

The results of the Hypothesis 2a indicate that high ambivalence towards rebranding leads to higher psychological discomfort. This finding supported previous ambivalence studies in that ambivalence is frequently associated with unpleasantness (van Harreveld et al., 2009) and psychological discomfort (Bell and Esses, 2002; Newby-Clark et al., 2002; Nordgren et al., 2006). The results also extended the existing literature that people experience psychological discomfort in an imposed change situation such as corporate rebranding, especially when they are asked to choose one side of the attitude (Pang and Keh, 2012; van Harreveld et al., 2009).

The resultis a higher tendency to alleviate this psychological discomfort among ambivalent individuals, by engaging in a) cognitive processing of relevant 
information; and b) making a choice (van Harreveld et al., 2009). They are motivated to search for more information if they have the resources and ability, representing an amplification effect. Driven by adecision accuracy motive (Armitage and Conner, 2000; Hudson, Maio and Esses, 2001; Jonas et al., 1997) especially when they lackof information and are under no time pressure, high-ambivalence individuals have higher intention to search for more information. This is reflected both by their stated intention in the thought listing tasks and implied by the numbers of thoughts that come to their mind, as statistically proven by hypothesis $2 \mathrm{~b}$. The amount of thoughts reflected their willingness to think about the issue at hand andthe higher number of thoughts indicated higher effort in information-processing. This result is consistent with Maio et al.'s $(1996,2000)$ studies in that ambivalent individuals experience a higher level of psychological arousal and process information carefully.

In this study, high-ambivalence individuals consistently recorded thoughts reflecting their 'indecisiveness' and 'willingness to search for more information'. For instance, some respondents indicated that they "need more information about the product and brand" (Resp. 2), "want to hear the opinions from others first" (Resp. 4), and "need suggestions and comments from friends who have bought it" (Resp. 21). There are also those who "have no confidence in the rebranded brand" (Resp. 67 and 75) and "want to think clearly about this brand" (Resp. 37). Some of them were indecisive due to their conflicted preferences (i.e. like the brand and dislike the other brand). Conversely, their low-ambivalence counterparts were more confident about their preferences as many of them were "satisfied with the brands" (Resp. 118) and "believe that the rebranding will produce good products" (Resp. 134, 136, 177) as "the quality is good" (Resp. 122, 129, 130, 171 and 173). Most importantly, these were "well-known" and "trusted" brands (Resp. 179, 181 and 183) and people were "loyal to the brands" (Resp. 150). There were also people who held negative attitudes and "did not like the brands" (Resp. 163, 164, 165,166, 168 and 194). The results indicated that consumer responses to corporate rebranding could be univalent, ambivalent or indifferent. The univalent (i.e. with low ambivalence) individuals hold either positive or negative attitudes toward corporate rebranding; while ambivalent individualshold moderate to strongly positive and negative attitudes.

The amount of thought processed also supported the hypothesis $2 b$ in that highambivalence individuals are willing to invest more cognitive effort in processing the rebranding message, compared to low-ambivalence individuals. Even though the majority of the respondents only reported one thought, high-ambivalence individuals constituted the largest proportion among those who processed more than one thought. This implies that high-ambivalence individuals comparatively have more thoughts and a higher willingness to search for more information to alleviate their psychological discomfort in an imposed change condition, rather than process the information in a simple manner.

The ambivalence measurement model of ATR permits a more detailed examination on consumers' reactions to corporate rebranding and allows the consumers' choice tasks to be expanded from "approach or withdrawal" (i.e. "willing to buy" and "not willing to buy" decisions) to: "approach; withdrawal and hold the buying decision". The last option reflects not only procrastination but also the amplification effect that "is problems focused [and] comprised of a variety of coping styles that involve a deeper examination of the decision problem" (Hanze, 2001, p. 969). 
In this study, high-ambivalence individuals consistently preferred 'hold buying'overthe 'buy rebranded brand' and 'buy other brands' options. These findings confirm the previous ambivalence literature in that high ambivalence leads to moderation in the attitude-behavioral link and puts a stop to decision making (Hanze, 2001). High-ambivalence individuals are comparatively more indecisive in decision making due to psychological discomfort and possess a higher intention to search for more information. They process information in a more controlled manner (Cunningham, et al., 2003) and invest more effort and deliberation (Jonas et al., 1997; Maio et al., 1996) to provide descriptions in a more systematic manner (Maio et al., 1996). The moderate to strongly held positive and negative reactions cause them to be indecisive when there is no clue to assist in decision making. They are either not clear about the outcome of the rebranding and hence need more information; or they are not convinced by the available information. This ambivalent attitude is hence held with less confidence and is more unstable (Pomerantz, Chaiken, and Tordesillas 1995).

Conversely, low-ambivalence individuals prefer approach or withdrawal. Their univalent strong attitudes toward the parent brands are 'more readily accessible' and could 'bias the perceptions of the attitude object and the context in which the behavior is performed' (Conner and Armitage, 2008, p. 275). These strong attitudes have stronger influence on the attitude-behavior intention (Armitage and Conner, 2000) to assist in decision making. The findings are consistent with Lord, Ross and Lepper (1979) who suggested that a biased assimilation process would cause interpretation of evidence in support for the original attitude. Low-ambivalence individuals will make buying choices based on their original attitudes toward the brand. In brief, the findings show that high- and low-ambivalence individuals portray distinct behavioral intentions in an imposed-change condition.

\section{Conclusion, Limitations and Future Study}

This study extends the previous literature by empirically examining and comparing across high and low ambivalent groups. Individuals with different levels of ambivalent attitudes portray different attitudinal and behavioral intentions. In particular, the findings confirm ambivalence towards rebranding as a valid construct that leads to moderation in approach and withdrawal actions. This study further validates the relationship between ambivalent attitudes and psychological discomfort and amplification effect. High-ambivalence individuals experience more psychological discomfort than their low-ambivalence counterparts and hence try to search for more information to alleviate this psychological discomfort. In addition, higher NFC was found to lead to higher ambivalence towards rebranding. Intrinsic motivator such as high need for cognition is found to lead to higher ambivalence towards rebranding.

There are a few limitations which need to be recognized. Firstly is the use of student samples. Although some researchers argued against the use of student samples(Schultz, 1969), many are attracted to its homogeneous nature (Calder, Philips, and Tybout, 1981). Student samples are suitable for use in theory applied research, as they better permit theoretical prediction (Lynch, 1982) and allow for less noise or extraneous variables (e.g., Brown and Stayman, 1992). This could decreasethe chances of making a false conclusion about whether there is a covariation 
betweenvariables under study. Secondly, consumer ambivalence towards rebranding was measured rather than manipulated, which limit the comparisonsamong ambivalence groups. Future study can utilize different rebranding messages that manipulate different levels of ambivalent reactions.Thirdly, the present study examines how ambivalent individuals make choice task decisions, without the examination of how ambivalence can be alleviated. As ambivalence towards rebranding is not a welcome consumer response to marketers, further examination of the possible variables in alleviating ambivalence would be meaningful. Brand name and message strength could be useful strategies to be utilized in the testing. Message strength is the most commonly manipulated message feature in persuasion message (Johnson, Maio and Smith-McAllen, 2005) and corporate name, is the most visible and impactful rebranding strategy (Melewar and Saunders, 2000; Muzellec and Lambkin, 2006). Consumers are expected to react differently to these manipulations.

In conclusion, consumers with different ambivalence levels react differently in terms of their cognitive, emotional and behavioral intention responses. A better understanding of consumer ambivalent attitudes enhances corporate rebranding success.

\section{Implications for Business Marketing Practices}

The present paper presents several important marketing and management implications. First of all, marketers' acknowledgement of corporate rebranding as an imposed change to customers is crucial (Piderit, 2000). This is because customers always have no say in a corporate rebranding decision; and in most of the time, they are the last to know. It is postulated in this paper that the rebranding messages are received and perceived by customers with mixed feelings; especially in a corporate rebranding caused by merger and acquisition. To consumers, corporate rebranding is an irreversible decision and an uncertain one. They are neither sure of the motives for nor the outcomes of the corporate rebranding. These customers might not resist (or simply cannot resist) but their cognitive response processes are not going to be simple, and not necessarily univalent. It is only through the recognition of ambivalence that marketers can plan and design their 'counter-ambivalence' rebranding campaign.

The findings provides empirical examination of ambivalent attitudes in corporate rebranding scenario. The results showed that high-ambivalence individuals have higher tendency to search for more information due to the experienced psychological discomfort. In conjunction to this, their "disagreement and disconfirmation of expectation van be important triggers for knowledge development" (Piderit, 2000, $\mathrm{p}$. 790). Piderit (2000) discussed the necessity to have divergent opinions about directions in a changed organization in order for groups to make wise decisions and for effective change.The organizational research findings show that "moving too quickly toward congruent positive attitudes in a proposed change might cut off the discussion and improvisation that may be required for revising the initial change proposal in an adaptive model" (Barr, Stimpert, and Huff, 1996; Burgelman, 1991 in Piderit, 2000, p. 790). Ambivalence hence helps to stimulate unlearning which is a necessary precursor to change (Pratt and Barnett, 1997) and a motivator for a new direction (Piderit, 2000). With proper marketing stimuli, marketers could have convinced the ambivalent individuals into buying action. 
Thirdly, the proposition of ambivalence towards rebranding construct in this dissertationalso indicated that univalent individuals are rather predictive. Their strongly held attitudes will convince them to buy/not buy when they hold positive/negative attitudes toward the corporate rebranding. However, it isinsufficiency in focusing only on those who have strong positive or negative attitudes, especially in a corporate rebranding. The high ambivalence individuals tend to put their buying decision on hold. This is similar to Piderit's (2000) argument that people need more time to process and make inferences about an organizational change. Perhaps an immediate action is not possible if no stimulus is involved to reduce consumer ambivalence. Marketers might encounter problems in controlling the pace and direction of the information search process by leaving these individuals to deal with their own ambivalent attitudes.People's intrinsic motivation such as need for cognition is proven to lead to higher ambivalence towards rebranding. In conclusion, marketers need to be aware of the different reactions to corporate rebranding, which consumers can beambivalent, univalent or indifferent.

\section{References}

Armitage, C. J. and Conner, M. (2000), “Attitudinal ambivalence: a test of three key hypotheses,"Personality and Social Psychology Bulletin, vol. 26, pp. 1421-1432.

Basinger, S. J. and Lavine, H. (2005), "Ambivalence, information and electoral choice,"American Political Science Review, vol. 99, no. 2, pp. 169-184.

Bell, D. W. and Esses, V. M. (1997), "Ambivalence and response amplification toward native people,"Journal of Applied Social Psychology, vol. 27, no. 12, pp. 1063-1084.

---, and Esses, V. M. (2002), “Ambivalence and response amplification: a motivational perspective,"Personality and Social Psychology Bulletin, vol. 28, pp. 1143-1152.

Brooks, M. E. and Highhouse, S. (2006), "Familiarity breeds ambivalence" Corporate Reputation Review, vol. 9, no. 2, pp. 105-113.

Brown, S. P. and Stayman, D. M. (1992),“Antecedents and consequences of attitude toward the ad: Ameta-analysis,"Journal of Consumer Research, vol. 19, No. June, pp. 34-51.

Cacioppo, J. T. and Petty, R. E. (1982), “The need for cognition,"Journal of Personality and Social Psychology, vol. 42, pp. 116-131.

---, Petty, R. E., and Kao, F. C. (1984), "The efficient assessment of need for cognition," Journal of Personality Assessment, vol. 48, no. 3, pp. 306-307.

---, Petty, R. E. and Morris, K. J. (1983), "Effects of NFC on message evaluation, recall, and persuasion,"Journal of Personality and Social Psychology, vol.45, no. 4, pp. 805-818.

Calder, B. J., Philips, L.W. and Tybout, A. M.(1981),"Designing research for application,"Journal of Consumer Research,vol. 8, pp. 197-207.

Conner, M. and Armitage, C. J. (2008), “Attitudinal ambivalence,” in Crano, W.D. and Prislin, R. (Ed.), Frontiers of Social Psychology, Psychology Press, NY, pp. 261-286.

----, and Flesh, D. (1998), Attitudes, intentions and ambivalence about having casual sex, School of Psychology, University of Leeds. 
Cunningham, W. A., Johnson, M. K., Gatenby, C. J., Gore, J. C. and Banaji, M. R. (2003), "neural components of social evaluation,"Journal of Personality and Social Psychology, vol. 85 , no. 4 , pp. 639-649.

Daly, Ai. and Moloney, D. (2004), "Managing corporate rebranding,"Irish Marketing Review, vol. 17 , no. 1/2, pp. 30-36.

Dhar, R., and Kim, E.Y. (2007), "Seeing the forest or the trees: implications of construal level theory for consumer choice," Journal of Consumer Psychology, vol. 17, no. 2, pp. 96100 .

Dickhauser, O. and Reinhard, M. A. (2006), "Factors underlying expectancies of success and achievement: the influential roles of NFC and general or specific self-concepts," Journal of Personality and Social Psychology, vol. 90, pp. 490-500.

Dunham, K. J. (2002), “KPMG Consulting Inc. picks Bearing Point for its new names,"Wall Street Journal, http://online.wsj.com/article/SB1033598317323402673.html

Gardberg, N. A., and Fombrun, C. J. (2002), "For better or worse: the most visible American corporate reputations," Corporate Reputation Review, vol. 4, no. 4, pp. 385-391.

Gunasti, K. and Ross, W.T. (2010), "How and when alphanumeric brand names affect consumer preferences,"Journal of Marketing Research, vol. XLVII, no. Dec, pp. 11771192.

Hanze, M. (2001), "Ambivalence, conflict, and decision making: attitudes and feelings in Germanytowards Nato's military intervention in the Kosovo war,"European Journal of Psychology, Vol. 31, pp. 693-706.

Haugtvedt, C. P., Petty, R. E. and Cacioppo, J. T. (1986), "Need for cognition and the use of peripheral cues," in Midwestern Psychological Association Meeting.

---. and Petty, R. E. (1992), "Personality and persuasion: need for cognition moderates the persistence and resistance of attitude changes,"Journal of Personality and Social Psychology, vol. 63, no. 2, pp. 308-319.

Hudson, G., Maio, G. R. and Esses, V. M. (2001), "The role of attitudinal ambivalence in susceptibility to consensus information,"Basic and Applied Social Psychology, vol. 23, no. 3, pp. 197-205.

Johnson, B. T., Maio, G. A. and Smith-McLallen, A. (2005), "Communication and attitude change: causes, processes, and effects,"The Handbook of Attitudes, pp. 617-669.

Jonas, K., Diehl, M. and Brömer, P. (1997), "Effects of attitudinal ambivalence on information-processing and attitude-intention consistency,"Journal of Experimental Social Psychology, vol. 33, pp. 190-210.

Judd, C. M. and Krosnick, J. A. (1989),“The structural bases of consistency among political attitudes: effects of political expertise and attitude importance,"in Pratkanis, A. R., Breckler, S. J. and Greenwald, A. G. (Ed.), Attitude Structure and Function, Lawrence Erlbaum, Hillsdale, NJ, pp. 99-129.

Keele, L. and Wolak, J. (2008),“Contextual sources of ambivalence,”Political Psychology, vol. 29 , no. 5 , pp. 653-675. 
Lassiter,D. G., Briggs, M. A. and Bowman, R. E. (1991), "NFC and the perception of ongoing behavior,"Personality and Social Psychology Bulletin, vol. 17, pp. 156-160.

Lavine, H. (2001), "The electoral consequences of ambivalence toward presidential candidates,"American Journal of Political Science, vol. 45, no. 4, pp. 915-929.

---, Christopher, J. and Steenbergen, M.(2012), The ambivalent partisan,Oxford University Press, Oxford.

Liberman, N. and Chaiken, S. (1991), "Value conflict and thought-induced attitude change,"Journal of Experimental Social Psychology, vol. 27, no. 3, pp. 203-216.

Lord, C. G., Ross, L. and Lepper, M. R. (1979), "Biased assimilation and attitude polarization: the effects of prior theories on subsequently considered evidence," Journal of Personality and Social Psychology, vol. 37, no. 11, pp. 2098.

Lynch J. G. (1982), "On the external validity of experiments in consumer research," Journal of Consumer Research, vol. 9, no. December, pp. 225-239.

Maio, G. R., Bell, D. W. and Esses, V. M. (1996), “Ambivalence and persuasion: the processing of messages about immigrant groups," Journal of Experimental Social Psychology, vol. 32, pp. 513-536.

Melewar,T. C., and Saunders, J. (2000), "Global corporate visual identity systems: using an extended marketing mix,"European Journal of Marketing, vol. 34, no. 5/6, pp. 538 - 550.

Muzellec, L., and Lambkin, M. (2006), “Corporate rebranding: destroying, transferring or creating brand equity?'European Journal of Marketing, vol. 40, no. 7/8, pp. 803-824.

Newby-Clark, I. R., McGregor, I., and Zanna, M. P. (2002), "Thinking and caring about cognitive inconsistency: when and for whom does attitudinal ambivalence feel uncomfortable?"Journal of Personality and Social Psychology, vol.82, pp. 157-166.

Nordgren, L. F., van Harreveld, F. and van der Pligt, J. (2006), “Ambivalence, discomfort, and motivated information-processing,"Journal of Experimental Social Psychology, vol. 42 , pp. $252-258$.

Öberg, C., Grundstrom, C. and Josson, P. (2011), “Acquisition and network identity change,"European Journal of Marketing, vol. 45, no. 9, pp. 1470-1500.

Oreg, S. and Sverdlik, N. (2011), “Ambivalence toward imposed change: the conflict between dispositional resistance to change and the orientation toward the change agent,"Journal of Applied Psychology, vol. 96, no. 2, pp. 337-349.

Pang, J., and Keh, H. T. (2011), "Affective reactions to attitudinal ambivalence: a goal attainment perspective,"American Marketing Association (Winter), pp. 218-226.

Perreault, W. D. J. and Leigh, L. E. (1989), "Reliability of nominal data based on qualitative judgments," Journal of Marketing Research, vol. XXVI, no. May, pp. 135-148.

Piderit, S. K. (2000), "Rethinking resistance and recognizing ambivalence: a multidimensional view of attitudes toward an organizational change," Academy of Management Review, vol. 25, no. 4,pp. 783-794. 
Pomerantz, E. M., Chaiken, S. and Tordesillas, R. S. (1995), “Attitude strength and resistance processes,"Journal of Personality and Social Psychology and Marketing, vol. 69, pp. 408-419.

Pratt, M. G. and C. K. Barnett (1997), "Emotions and unlearning in Amway recruiting techniques promoting change through safe ambivalence,"Management Learning, vol. 28, no. 1 ,pp. $65-88$.

Rudolph, T. J. and Popp, E. (2007), “An information-processing theory of ambivalence,"Political Psychology, vol. 28, no, 5, pp. 563-585.

Schultz, D. P. (1969), "The human subject in psychological research," Psychological Bulletin, vol. 72, pp. 214-228.

Simonin, B. L. and Ruth, J. A. (1998), "Is a company known by the company it keeps? Assessing the spillover effects of brand alliances on consumer brand attitudes,"Journal of Marketing Research, vol. XXXV, pp. 30-42.

Stuart, H., and Muzellec, L. (2004), “Corporate makeovers: can a hyena be rebranded?"Journal of Brand Management, vol. 11, no. 6, pp. 472-482.

Sverdlik, N. and Oreg, S. (2009),"Personal values and conflicting motivation forces in the context of imposed change,"Journal of Personality, vol. 77, no. 5, pp. 1437-1465.

Tesser, A. and Leone, C. (1977), "Cognitive scheme and thought as determinant of attitude change,"Journal of Experimental Social Psychology, vol. 13, pp. 340-356.

Tetlock, P. E. (1989), “Structure and function in political belief systems,”in Pratkanis, A. R., Breckler, S. J. and Greenwald, A. G. (Ed.),Attitude Structure and Function, Lawrence Erlbaum, Hillsdale, NJ, pp. 129-151.

Thompson, M. M., and Holmes, J. G. (1996), “Ambivalence in close relationship. conflicted cognitions as a catalyst for change," in Sorrentino, R. M. and Higgins, E.

T.(Ed.),Handbook of Motivation and Cognition, Vol. 3, Guilford Press, New York, NY, pp. 497-530.

---, and Zanna, M. P. (1995), "The conflicted individual: personality-based and domainspecific antecedents of ambivalent social attitudes,"Journal of Personality, vol. 63, no. 2, pp. 259-288.

---, Zanna, M. P. and Griffin, D. W. (1995), "Let's not be indifferent about (attitudinal) ambivalence," Attitude Strength: Antecedents and Consequences, Lawrence Erlbaum, Hillsdale, NJ,pp. 361-386.

Ting, S. C. (2012), "How Need for Cognition Moderates the Influence of Country of Origin and Price on Consumer Perception of Quality,"Social Behavior and Personality, vol. 40, no. 4 , pp. 529-544.

Trond, R. K., .Finskud, L., Tornblom, R. and Hogna, E. (1997), "Brand consolidation makes a lot of economic sense: but only one in five attempts succeeds,"The McKinsey Quarterly, vol. 4, no. Autumn, pp. 189-195.

Yang, D., Davis, D. A. and Robertson, K. R. (2012), "Integrated branding with mergers and acquisitions," Journal of Brand Management, vol. 19, no. 5, pp. 438-456. 
van Harreveld, F., van der Pligt, J. de Vries, N. K., Wenneker, C., and Verhue, D. (2004), "Ambivalence integration in attitudinal judgment,"British Journal of Social Psychology, vol. 43, pp. 431-447.

---, van der Pligt, J. and de Liver, Y. (2009), "The agony of ambivalence and ways to resolve it: introducingthe MAID Model,"Personal Social Psychology Review, vol. 13, pp. 45-61.

---, Rutjens, B. T., Nordgren, L. and van der Pligt, J. (2009), “Ambivalence and decisional conflict as a cause of psychological discomfort: feeling tense before jumping off the fence,"Journal of Experimental Social Psychology, vol. 45, pp. 167-117.

Wilson, T. D., Kraft, D. and Dunn, D. S. (1989), "The disruptive effects of explaining attitudes: the moderating effect of knowledge about the attitude object,"Journal of Experimental Social Psychology, vol. 25, pp. 379-400.

Wood, W., Kallgren, C. and Priesler, R. M. (1985), "Access to attitude-relevant information in memory as a determinant of persuasion: the role of message attributes," Journal of Experimental Social Psychology, vol. 21, pp. 73-85.

Zimmerman, I., Redker, C., and Gibson, B. (2011), "The role of faith in intuition, need for cognition and method of attitude formation in implicit-explicit brand attitude relationship strength,"Journal of Consumer Psychology, vol. 21, pp. 290-301.

Zemborani, M. R., and Johar, V. G. (2007), “Attitudinal ambivalence and openness to persuasion: a framework for interpersonal influence,"Journal of Consumer Research, vol.33, no. March, pp. 506-514. 